\title{
Building a systematic framework for an entrepreneurial university
}

\author{
Aurik Gustomo ${ }^{1, *}$, Astri Ghina ${ }^{2}$ \\ ${ }^{1}$ School of Business and Management (SBM), Institut Teknologi Bandung (ITB), Bandung, Indonesia \\ ${ }^{2}$ Faculty of Economics and Business, Telkom University, Bandung, Indonesia
}

\section{ARTICLE INFO}

\section{Article history:}

Received 20 March 2017

Received in revised form

22 May 2017

Accepted 14 June 2017

\section{Keywords:}

Entrepreneurial

Entrepreneurial University

Conceptual framework

Systematic framework

\begin{abstract}
A B S T R A C T
The importance of creating an entrepreneurial university is vital to achieving sustainable national economic growth. Despite numerous studies conducted to elaborate an entrepreneurial university conceptualization, framework and measurement, the results are mostly fragmented and remain at an embryonic stage. The research reported here proposes a systematic framework for an entrepreneurial university as the preliminary stage for further development in research and practice.
\end{abstract}

(C) 2017 The Authors. Published by IASE. This is an open access article under the CC BY-NC-ND license (http://creativecommons.org/licenses/by-nc-nd/4.0/).

\section{Introduction}

The concept of an Entrepreneurial University (EU) plays a key role within a knowledge economy since considerable learning is developed within a university through the three core activities of teaching, research, and community services. A university is considered to be the vital catalyst of national economic and social development. Therefore, for these reasons, many beneficiaries of this phenomenon are attempting to foster the development of an entrepreneurial university. Recently, although several studies have tried to explore the phenomenon, only limited, evidencebased and relevant literature exists on the concept and framework of an entrepreneurial university (Sooreh et al., 2011). The research reported here is the preliminary stage in building a systematic framework for an entrepreneurial university. Its focus is that of exploring such an institution's conceptualization from ontological, epistemological, and methodological viewpoints. This stage is very important in fulfilling the need for a more holistic view of constructing a systematic framework for this phenomenon.

\section{Literature review}

The importance of creating an entrepreneurial university is vital to achieving sustainable national economic growth. Despite several studies conducted

\footnotetext{
* Corresponding Author.

Email Address: aurik@sbm-itb.ac.id (A. Gustomo)

https://doi.org/10.21833/ijaas.2017.07.017

2313-626X/C 2017 The Authors. Published by IASE.

This is an open access article under the CC BY-NC-ND license

(http://creativecommons.org/licenses/by-nc-nd/4.0/)
}

to explore this institutional phenomenon, the current literature on the subject has been reviewed in an unsystematic way (Rothaermel et al., 2007). The results of investigation into the concept of the entrepreneurial university, its framework and measurement, are mostly fragmented and remain in their preliminary phase (Guerrero and Urbano, 2012; Salamzadeh et al., 2011). This knowledge gap requires the adopting of a holistic view in order to build a systematic framework for an entrepreneurial university (Zhou, 2008). The purpose of this research is to better understand the phenomena and provide some guidance as to its future agenda.

The university must transform its internal culture in order to provide an environment conducive to supporting its efforts to become an entrepreneurial institution. The case study conducted by Philpott et al. (2011) revealed that an inherent motivation to undertake entrepreneurial activity is better than a top-down approach to fostering an entrepreneurial university. The latter should address the obstacles regarding an understanding of the concept of the entrepreneurial university which is represented in institutional goals and objectives. Zhou (2008) found that the pathway to an entrepreneurial university begins with government-industry-university collaboration. Such collaboration starts with industry funding of academic research which has the potential to be commercialized. Sergey et al. (2015) reviewed the USA's experience in creating the new national innovative infrastructure for Russia-the Proof of Concept Center (POOC), highlighting the correlation between the establishment of POCC and the increasing number of innovative companies. Another study was conducted by Chang et al. (2016) which highlighted regressions suggesting that both levels of Research Ambidexterity (RA) facilitate 
departmental and individual commercial performance. The paper concludes that the development of RA in entrepreneurial universities should be considered as building multi-level relationships between universities, departments and individuals. Liu (2012) stated that in China, universities have always been linked with industry. Huazhong University of Science and Technology originated from the demands of industrial development. Alexandera and Evgeniy (2012) stated that Russia has built an innovative infrastructure, engendered an entrepreneurial culture, and actively promoted the concept an entrepreneurial university. Indeed, such institutions were the original drivers of the Triple Helix model which, in brief, describes the development of innovation involving multiple relationships between university, industry, and government.

The EC (2012) proposed guidelines for EUs consisting of seven elements; Leadership and Governance, Organizational Capacity, People and Incentives, Entrepreneurship development in teaching and learning, Pathways for entrepreneurs, University - business/external relationships for knowledge exchange, the Entrepreneurial University as an internationalized institution and Measuring the impact of the Entrepreneurial University. This framework constitutes an assessment tool to identify the university's strengths, weaknesses and identify ways forward to foster the developments of EU characteristics. Ziyae and Tajpour (2016) proposed the model of driver factors toward an entrepreneurial university. The result of their study has suggested the positive and significant effects of the organizational, individual, institutional, and environmental factors on entrepreneurial universities in science and technology parks. Another model of entrepreneurial university proposed by Guerrero et al. (2015) promoted the three core missions of teaching, research, and entrepreneurial activities to develop economic and social aspects. In particular, the outcomes of its missions are the development of human capital, knowledge capital, social capital, and entrepreneurship capital.

There are four classifications of articles on EUrelated issues, namely; the Entrepreneurial University Framework, Institutional Environment, Entrepreneurial Activities, and Entrepreneurial Impacts. Most authors conduct empirical studies with the main focus on entrepreneurial activities and the entrepreneurial environment. Few studies present a conceptualization of EU and even fewer build on a framework to elaborate on it.

\section{Research methodology}

This conceptual research is used deductive method to construct the framework of Entrepreneurial University. The steps to build the framework are as follows:

a. Problem statement b. Preliminary literature review to find the research gap

c. Constructing the framework to fill the research gap

1) Phase 1: Ontological assumptions

2) Phase 2: Epistemological assumptions

3) Phase 3: Methodological assumptions

4) Phase 4: Integrating concept

5) Phase 5: Synthesizing the concept

6) Phase 6: Building the framework of an Entrepreneurial University

d. Discussion to analyze the contribution of framework

e. Conclusions to summarize the main findings and scientific contributions

\section{Constructing the proposed conceptual framework}

A systematic framework constitutes a basic, wellorganized, conceptual structure incorporating the comprehensive principles within a particular field of knowledge. It indicates the clearly-structured responsibilities of key stakeholders and patterns of interaction between them. The procedures necessary to follow when building this type of systematic framework are as follows (Ghina et al., 2015).

\subsection{Phase 1: Ontological assumptions}

Ontological assumptions relate to knowledge of the way things are, the nature of reality, real existence, and real action (Jabareen, 2009). Based on the topic of this research, the ontological questions focus on the form and nature of reality in the entrepreneurial university and how we understand its existence. The answer to these questions is external to the researcher and can be both captured by our senses and predicted on the basis of knowledge of previous causal events.

In effect, the entrepreneurial university is playing a vital role in the economic development of a range of countries. Universities, particularly those entrepreneurial in nature, are important actors in the "Triple Helix" of University-IndustryGovernment relations that promotes science-based innovative product/services (Etzkowitz and Zhou, 2006). This means the reality of the entrepreneurial university is assumed to be a vital aspect of overall economic development. However, in the real world, some beneficiaries of this phenomenon behave in an ambiguous manner starting from its conceptualization through to framework and measurement. In other words, a holistic view of the relevant literature that could guide universities to act entrepreneurially is lacking.

The reality of low entrepreneurial impact, both locally and globally, leads universities to stimulate job and wealth creation through excellence in education, research and by enhancing the third mission of service, that of being expected to support the commercializing of research, licensing of technology, creating of university spin-offs, 
introducing of entrepreneurship programs, and expanding of university-industry relations. Universities are being encouraged to take an entrepreneurial path (Foss and Gibson, 2015). In turn, entrepreneurial universities take the lead in developing their economic and social aspects. An entrepreneurial university is objectively interpreted and emerges in an ongoing manner through a series of entrepreneurial processes within higher education boundaries.
The next task is to map the spectrum of disciplinary literature regarding the phenomenon of the entrepreneurial university. This process includes identifying text types and other sources of data. The term 'entrepreneurial university' can be found in the discipline of education within an entrepreneurship context. The term 'Entrepreneurial University' is defined in previous literature on the subject. The mapping of the definitions adapted from GarcíaAracil et al. (2013) can be seen in Table 1.

Table 1: Mapping of the definition of an Entrepreneurial University (García-Aracil et al., 2013)

\begin{tabular}{|c|c|}
\hline TERM & DEFINITION \\
\hline $\begin{array}{l}\text { Entrepreneurial } \\
\text { University }\end{array}$ & 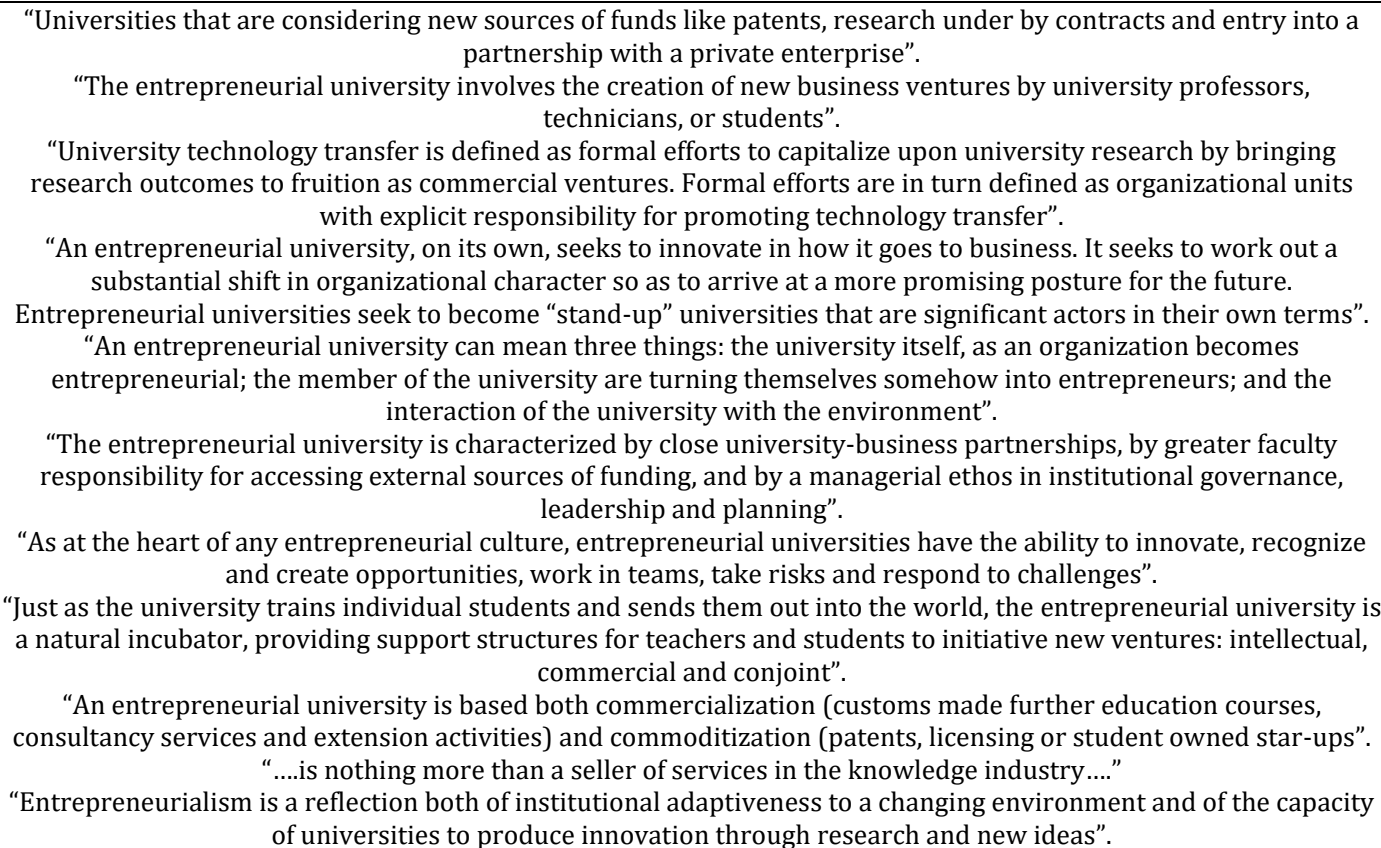 \\
\hline
\end{tabular}

Thus, according to the definition contained in previous literature, the entrepreneurial university can be understood as a flexible organization that interacts with its social and economic environment. This enables it to stimulate job and wealth creation by excelling in education, research, and enhancing the third mission of service that the latter is expected to promote. This mission covers the commercializing of research, licensing of technology, creating of university spin-offs, introducing of entrepreneurship programs, expanding of university-industry relations, together with other entrepreneurial activities.

\subsection{Phase 2: Epistemological assumptions}

Epistemology is also concerned with providing a philosophical grounding for deciding what kinds of knowledge are possible and how we can ensure that they are both adequate and legitimate (Crotty, 2003).

For the epistemological question of how we know what entrepreneurial universities really are the answer lies in the knowledge of the entrepreneurial university being objective and generated deductively from the theory of entrepreneurship? The knowledge and concept of the entrepreneurial university are created through interaction between people and their environment (the learning process) within higher education boundaries. Within this view, knowledge of the entrepreneurial university is regarded as an objective phenomenon. Universities are being encouraged to take an entrepreneurial turn in identifying the transition that challenges them as institutions, beyond their first mission (education/teaching) and second mission (research) (Foss and Gibson, 2015).

\subsection{Phase 3: Methodological assumptions}

Methodology is the strategy, plan of action, process or design lying behind the choice and use of particular methods and linking the choice and use of these methods to the desired outcomes (Crotty, 2003). The methodological aspect explains how a researcher forms perceptions about a specific phenomenon being investigated.

The question underlying methodological assumptions is that of how a researcher forms perceptions about the phenomenon of the entrepreneurial university. The transactional nature of this research topic is acquired through the deductive method; hence the framework could be applied in any universities. It is important to review the previous literature regarding how to develop an entrepreneurial university, so that it can be synthesized when building a systematic framework. 
The methodological assumptions of how to develop an entrepreneurial university is a longitudinal process of social interaction within higher education boundaries. Moreover, it should have consequences for the theoretical framework of such educational institutions and use of theory in the field of entrepreneurship.

\subsection{Phase 4: Integrating concept}

The aim in this phase is to integrate the process in phases 1, 2 and 3; and to group together the concept that emerges from the literature. This phase describes the ontological, epistemological and methodological assumptions related to entrepreneurial graduates. The framework path is illustrated in Fig. 1.

\subsection{Phase 5: Synthesizing the concept}

This phase is iterative and includes repetitive synthesis until the general theoretical framework plausible. It is explained through an in-depth discussion of how to develop an entrepreneurial university. The conceptual framework starts from three core missions within the university consisting of Teaching Activities, Research Activities, and Service Activities.

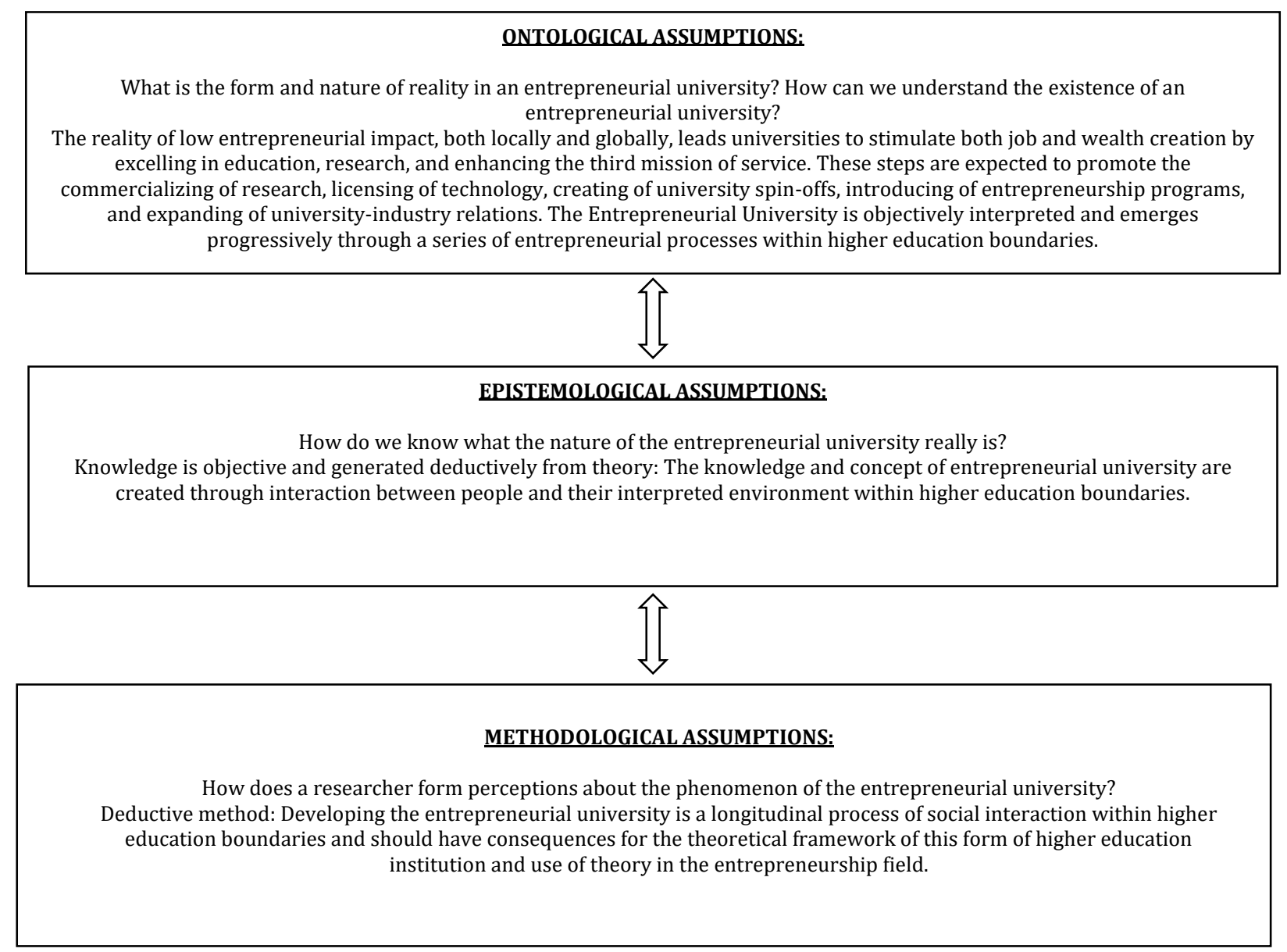

Fig. 1: The framework path of Entrepreneurial University

\subsection{The first mission: Teaching activities}

Universities educate and train students who become professionals or entrepreneurs after graduation. Hence, entrepreneurial universities could have an impact on economic concepts about human capital. The latter term refers to the stock of competencies, knowledge, abilities, and skills gained through education and training. Therefore, entrepreneurial universities could contribute to economic impact through the generation, attraction, and retention of talented human capital and entrepreneurs (Guerrero et al., 2015). The outcomes of the first mission are entrepreneurial mindsets and skills which promote a wide range of career opportunities including intrapreneurs, selfemployment, and entrepreneurs (ACEEU, 2016), a process referred to as human investment (Guerrero et al., 2015). Entrepreneurship education within a university has the goal of developing entrepreneurial graduates as human capital who attain a high standard of competence, either as professionals or entrepreneurs. An entrepreneurial graduate is a person who has successfully completed a course of study and demonstrates the spirit or mindset, behavior, attitude, and skills of an entrepreneur. Such behavior includes; opportunity-seeking, initiative-taking, ownership of development, commitment to seeing things through to a successful conclusion, personal locus of control (autonomy), intuitive decision-making with limited information, networking capacity, strategic thinking, negotiation capacity, selling/persuasive capacity, achievement orientation, and the willingness to take risks in order 
to make a profit, and addressing economic and social needs (Ghina et al., 2015).

Institutional goals can be placed on the input side as a trigger to develop graduates' competencies. In order to support their goals, universities create course content, incorporating this into curricula related to its specific goals and target audiences, and an appropriate learning approach is required to deliver it effectively. To achieve goals, there are three key actors involved within a university setting, namely students, staff, and institution. They have their own attributes within the education process, such as ability, opportunity and incentive aspects (Piper, 1993). This framework is used as a guideline for effective learning within a university (Ghina et al., 2015).

\subsubsection{The second mission: Research activities}

Research activities such as copyrights, patents, licenses, and trademarks are identified to generate, transfer and commercialize new knowledge. Expert researchers who facilitate both internal and external innovation and knowledge transfer at an institution will have an impact on economic and social aspects (Guerrero et al., 2015). The outcomes of the second mission consist of income and intellectual contributions with a high potential for commercialization (ACEEU, 2016). This is referred to as knowledge investment (Guerrero et al., 2015).

\subsubsection{The third mission: Third stream activities}

The Third Mission complements the two missions of teaching and research. Alongside these more traditional roles, universities and public sector research establishments need to play a greater role as stimulators and facilitators of knowledge transfer to business and society. This Third Mission supports the structures, processes and outcomes of interaction between universities and the wider community. Via such Third Mission activities, universities seek to generate, apply and use knowledge and capabilities outside academic environments. The Third Mission covers not only the commercialization of academic knowledge through collaboration with industry, patenting and licensing, creation of spin-off companies, but also includes participation in policy-making and involvement in social and cultural life. The complexity of this issue reflects the richness of the bounds linking HEIs to society at large (Molas-Gallart et al., 2002). The Third Mission is interpreted as a university's social and entrepreneurial activities within the wider community. Entrepreneurial activities can take a variety of forms, joint ventures, spin-offs, start-ups, incubators and science parks being some of the tools used by universities to promote the development of new businesses. Universities also set up business competitions and funding facilities to support entrepreneurial activities (Molas-Gallart et al., 2002).
Entrepreneurial activities also focus on the creation of new companies that involve stakeholders across all university levels; university management, academicians, researchers, and potential entrepreneurs among under- and postgraduate students. An entrepreneurial university could generate new start-ups that address the needs of industry and society (Guerrero et al., 2015). The goals of the Third Mission include social and entrepreneurial investment (Guerrero et al., 2015; Molas-Gallart et al., 2002).

\subsection{Phase 6: Building the framework of an Entrepreneurial University}

This phase is a re-synthesis comprising several concepts necessary to build the systematic framework of an EU. The form of that framework covers the differences between what universities have (abilities), what they support (opportunity), and what they provide (incentive) in each of three basic activities (Teaching, Research, and Service). For each basic activity, the framework includes a trio of important stakeholders (student, lecturer, and institution) each with their own respective roles within the university. The effective conditions necessary for fulfilling the three missions of a university are the internal stakeholder's ability to identify appropriate opportunities and experience adequate incentive if the activities are carried out. This process is known as engagement. A systematic framework for an entrepreneurial university can be seen in Fig. 2. The outcome of the first mission is engagement with learning which can be characterized by the creation of entrepreneurial students / graduates as a form of human investment. The means of measuring the output of the first mission is students or graduates' level of entrepreneurial competence. The outcome of the second mission is engagement with research which can be characterized by the promotion of science / technology commercialization as knowledge investment. Measuring the output of second mission's centers on the number and quality of publications, Intellectual Property Right (IPR), and start-ups. The outcome of the Third Mission is community engagement which can be characterized as the applicability and exploitation of science/technology commercialization as social investment. Numbers of contracts, contract fees, and the impact on industry, society, and the environment are used to quantify Third Mission output.

Universities can provide the appropriate environments for student and lecturer/ academic staff to execute their respective roles effectively. These environments should be conducive to transforming institutions into entrepreneurial universities and should possess clarity of vision and strategy, effective leadership and governance, relevant policy and practice in order to develop an entrepreneurial culture and mindset. The entrepreneurial university builds on co-innovation and co-creation within the three institutional 
missions regarding sustainability. The university must have an "Assurance of Learning" to guarantee the quality of its three core activities. The entrepreneurial university's goals and objectives must be stated clearly and understood by all key stakeholders (student, lecturer, institution). Furthermore, the university has to use the outcome- based approach to conducting three core activities (teaching, research, and community service). The important elements are the regular checking of outputs/outcomes with systematic evidence gathering from measurements taken in order to achieve continuous improvement.

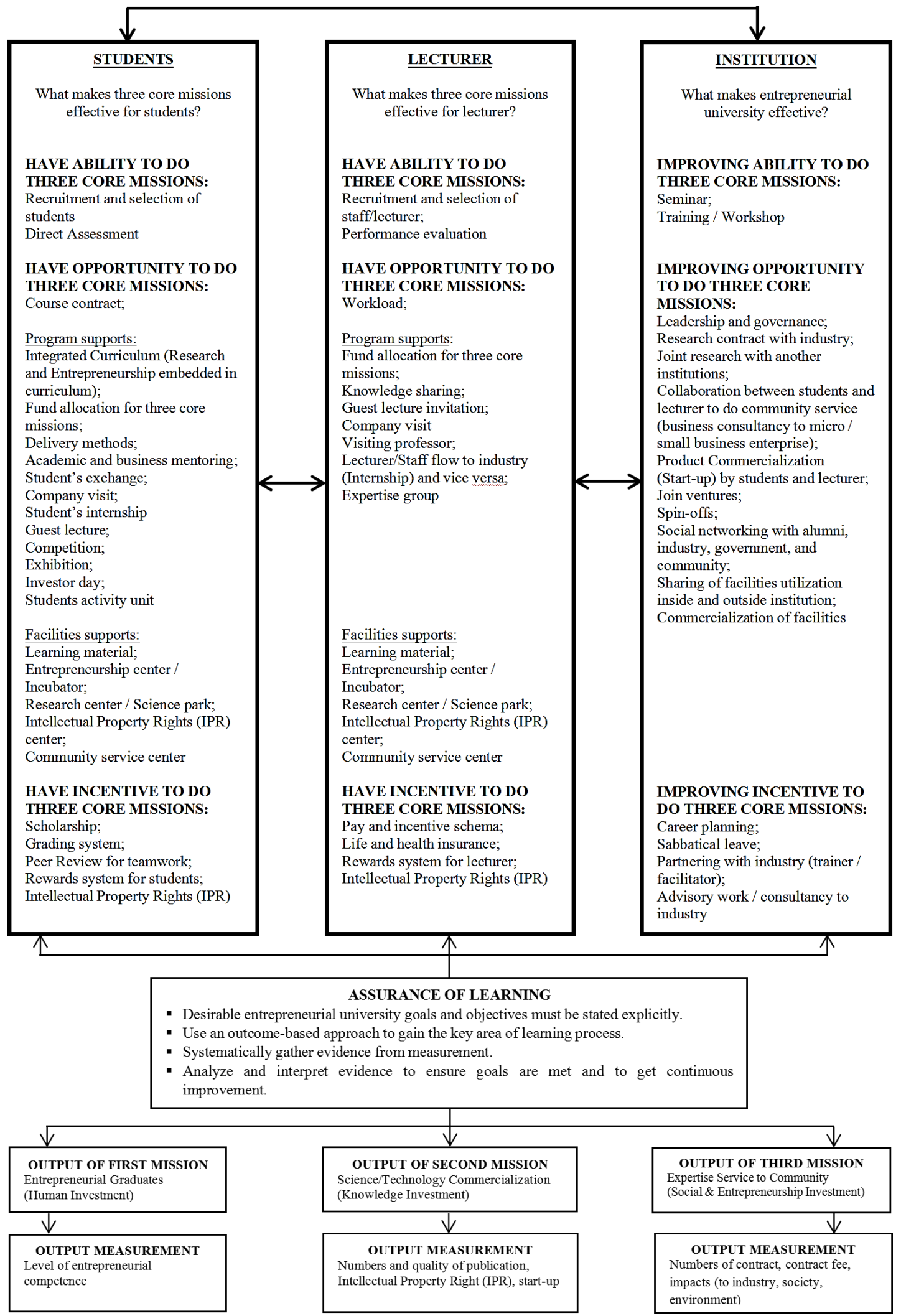

Fig. 2: The framework of Entrepreneurial University (EU) 


\section{Discussion}

The main finding of this research is the conceptual model analysis of a systematic framework for EU as a means of developing an entrepreneurial university. This framework covers all key actors within the university. Each actor has his/her own role in creating effective teaching, research, and third stream activities. The scientific contribution of this research is the use of the proposed systematic framework in pursuit of several goals: (a) to understand the priorities for effective teaching in order to create better human investment, (b) to identify areas of opportunity for learning improvement, (c) to understand the priorities for effective research as a means of promoting better knowledge investment, (d) to identify areas of opportunity for research improvement, (e) to understand the priorities for effective third stream activities, thereby encouraging social and entrepreneurship investment, (f) to identify areas of opportunity for third stream activities improvement, (g) to help university management understand the key stakeholders' needs to develop entrepreneurial university, (h) to give better understanding of how to measure the output from three core activities within a university.

The study conducted by Salamzadeh et al. (2011) proposed a systematic framework for an entrepreneurial university using the Input-ProcessOutput-Outcome (IPOO) Model. The framework covers all vital elements of learning for an entrepreneurial university such as input, process, output, and outcome. However, there is unclear structured responsibility of key stakeholders within the university (students, staff, institution) related to those main valuable aspects. The IPOO model does not show the pattern of interaction among its key stakeholders and the assurance of learning. Meanwhile, Salamzadeh et al., (2011) considered the entrepreneurial university to be an Entrepreneur Organization that emphasizes three defining characteristics: the university has to implement an entrepreneurial management style (institution); the members should act entrepreneurially (student and staff); and the institution has a clear entrepreneurial pattern to interact with its environment (student, staff, and institution). The guiding framework proposed by the EC (2012) covered seven factors likely to be typical of an EU. These include helping universities to identify their current situation and find opportunities to foster the characteristics of an EU. However, there is unclear structured responsibility regarding the key stakeholders within the university (students, staff, institution) related to those factors. Besides, the questionnaires devised by the EC (2012) covered general, rather than detailed, statements to measure these seven EU characteristics. The EU framework proposed by them does not categorize the characteristics into the three core missions of teaching, research, and service. Nor does it clearly classify which factors are related to each aspect of these three core missions.
Ultimately, this framework's output and the means of measuring it if the university does succeed in fostering those seven EU factors are unclear.

The systematic framework proposed by this study covers three important key stakeholders within a university, namely; student, lecturer, and institution. All key stakeholders have their own role and responsibility regarding the three core activities within university; teaching activities, research activities, and third stream activities. The effective process toward developing an entrepreneurial university involves engagement with the three core activities within the educational institution concerned. This systematic framework can be used as the guidelines to identify the priorities for making continuous improvement towards sustainability when developing an entrepreneurial university. The limitation of this framework is not divided the assurance of learning for each core mission, it needs further exploration if the student, lecturer, and institution aspect has the same or different assurance of learning.

\section{Conclusion}

The main findings of this conceptual research comprise; the need for a systematic framework as a guideline for effective teaching, research, and third stream activities to develop an entrepreneurial university, the institution's need to manage three key stakeholders, namely students, staff, and the institution itself in order to achieve these goals, and the assurance of learning so as to guarantee the effectiveness of the three core missions that also has to be well-managed by the institution. Previous studies discussed the driver factors of an entrepreneurial university only partially, focusing their research mainly on entrepreneurial activities and institutional environment. Few explored the collaborative work between several elements within an entrepreneurial university and the means of developing such an entity. This research offers a fully systematic approach to exploring abilities, opportunities and incentives in order to foster the engagement of key university stakeholders. This systematic framework is expected to review the roles of students, lecturers and the institution in creating satisfactorily three core mission activities within the university.

The scientific contribution of this research is a building process of the proposed systematic framework as a guideline when investigating the phenomenon of the EU. It can be used to describe successful practices in managing university capabilities and activities to develop truly entrepreneurial educational institutions. This approach is expected to enable the exploration of all, rather than only some aspects which are necessary for effective core mission activities to occur within a university.

It is expected that this conceptual research will provide a guideline for practitioners such as policymakers, lecturers, researchers, and curriculum 
developers for the development of a systematic EU framework useful to developing an entrepreneurial university. This creates both more knowledge and technology commercialization that could increase job creation and sustainable economic growth. The future research suggested consists of conductmapping and evaluation to gain a better understanding of a university's core mission effectiveness in order to further its development as an entrepreneurial entity. This mapping and evaluation should be applied to several universities as a means of gaining useful insight into the optimum learning practices. Cross-case analysis can be conducted to discover patterns useful to formulating a theory of the entrepreneurial university.

\section{References}

ACEEU (2016). Accreditation types and levels. Accreditation Council for Engaged and Entrepreneurial Universities. Available online at: https://www.aceeu.org/index/ accreditationtypes, accessed at September, 15th, 2016.

Alexandera U and Evgeniy P (2012). The entrepreneurial university in Russia: From idea to reality. Procedia-Social and Behavioral Sciences, 52: 45-51

Chang YC, Yang PY, Martin BR, Chi HR, and Tsai-Lin TF (2016). Entrepreneurial universities and research ambidexterity: A multilevel analysis. Technovation, 54: 7-21

Crotty M (2003). The foundations of social research: Meaning and perspectives in the research process. Sage Publications, London, UK.

EC (2012). A guiding framework for entrepreneurial university. European Commission. Available online at: https://www.oecd.org/site/cfecpr/EC-OECD Entrepreneurial Universities Framework.pdf

Etzkowitz H and Zhou C (2006). Triple helix twins: Innovation and sustainability. Science and Public Policy, 33(1): 77-83.

Foss L and Gibson DV (2015). The entrepreneurial university: Context and institutional change. Routledge, Abingdon, UK.

García-Aracil A, Castro-Martínez E, Jiménez-Sáez F, and ArroyoVázquez M (2013). What might an entrepreneurial university constitute?. In the EU-SPRI Forum Conference, Universidad Autónoma de Madrid, CSIC-UPV - Instituto de Gestión de la Innovación y del Conocimiento (INGENIO), Madrid, Espían. Available online at: https://digital.csic.es/bitstream/10261/ 107944/1/What might an entrepreneurial.pdf

Ghina A, Simatupang TM, and Gustomo A (2015). Building a Systematic Framework for Entrepreneurship Education. Journal of Entrepreneurship Education, 18(2): 73-97.
Guerrero M and Urbano D (2012). The development of an entrepreneurial university. Journal of Technology Transfer, 37(1): 43-74

Guerrero M, Cunninghamb JA, and Urbano D (2015). Economic impact of entrepreneurial universities' activities: An exploratory study of the United Kingdom. Research Policy, 44(3): 748-764.

Jabareen Y (2009). Building a conceptual framework: philosophy, definitions, and procedure. International Journal of Qualitative Methods, 8(4): 49-62.

Liu Y (2012). Does entrepreneurial university really exist in China?. Journal of Knowledge-based Innovation in China, 4(2): 88-103.

Molas-Gallart J, Salter A, Patel P, Scott A, and Duran X (2002). Measuring third stream activities. Final Report to the Russell Group of Universities, SPRU: Science Policy Research Unit, University of Sussex, Brighton, UK. Available online at: http://www.academia.edu/download/3460866/russell_repo rt_thirdStream.pdf

Philpott K, Dooley L, O'Reilly C, and Lupton G (2011). The entrepreneurial university: Examining the underlying academic tensions. Technovation, 31(4): 161-170.

Piper DW (1993). Quality management in university. Australian Government Publishing Service, Canberra, Australia.

Rothaermel FT, Agung SD, and Jiang L (2007). University entrepreneurship: A taxonomy of the literature. Industrial and Corporate Change, 16(4): 691-791

Salamzadeh A, Salamzadeh Y, and Daraei MR (2011). Toward a systematic framework for an entrepreneurial university: A study in Iranian context with an IPOO model. Global Business and Management Research: An International Journal, 3(1): 3137.

Sergey AB, Alexandr DB, and Sergey AT (2015). Proof of concept center-A promising Tool for innovative development at entrepreneurial universities. Procedia-Social and Behavioral Sciences, 166: 240-245.

Sooreh LK, Salamzadeh A, Safarzadeh H, and Salamzadeh Y (2011). Defining and measuring entrepreneurial universities: A study in Iranian context using importance-performance analysis and TOPSIS technique. Global Business and Management Research: An International Journal, 3(2): 182199.

Zhou C (2008). Emergence of the entrepreneurial university in evolution of the triple helix. Journal of Technology Management in China, 3(1): 109-126

Ziyae B and Tajpour M (2016). Designing a comprehensive model of entrepreneurial university in the science and technology parks. World Journal of Entrepreneurship, Management and Sustainable Development, 12(3): 267-280. 